\title{
Educação em Ciência e as “Novas” Tecnologias
}

\section{Science teaching and the "new" technologies}

\author{
Margarete Valverde de Macedo ${ }^{1}$ mvmacedo@biologia.ufrj.br \\ Milena de Sousa Nascimento ${ }^{2}$ \\ Luiz Bento ${ }^{3}$
}

\section{RESUMO}

É crescente no Brasil a preocupação com Educação em Ciência e são inúmeras as iniciativas que utilizam tecnologias educacionais nesse contexto. Entretanto, muito ainda se discute sobre as melhores formas de usar essas tecnologias na educação em ciência. Diante disso, apresentamos uma introdução sobre alguns termos relacionados à educação em ciência e um pouco sobre a importância e a necessidade da formação da consciência científica para o exercício pleno da cidadania. Seguimos definindo o que são as "novas" tecnologias e finalizamos exemplificando formas de uso desta tecnologia para a educação em ciência.

Palavras-chave: Educação em ciência, alfabetização científica, divulgação científica, novas tecnologias.

\section{ABSTRACT}

The concern in Brazil with Science education is growing, and numberless are the initiatives that use educational Technologies in this context. However, there is much still being discussed about the better forms of using such technologies in science education. Upon this, we present an introduction about some terms relationed to science education and a little about the importance and need of the formation of scientific conscience for the full exercise of citizenship. We follow defining what are the "new" technologies and finish exemplifying the forms of use of such technology in science education.

Key-words: Science education, scientific alphabetization, scientific divulgation, new technologies.

1 UFRJ - Universidade Federal do Rio de Janeiro, Rio de Janeiro, RJ.

2 UFRJ - Universidade Federal do Rio de Janeiro, Rio de Janeiro, RJ.

3 UFRJ - Universidade Federal do Rio de Janeiro, Rio de Janeiro, RJ. 


\section{EDUCAÇÃO EM CIÊNCIA}

A preocupação com educação em ciência é recente no Brasil, mas em países da Europa e nos Estados Unidos essa preocupação já existe desde o século XIX, com a inclusão da disciplina de Ciências no currículo das escolas (DeBoer, 2000). Naquele primeiro momento, o ensino de ciências acontecia apenas nas escolas e tinha como foco principal o ensino prático das ciências, mas também trabalhava o desenvolvimento do pensamento indutivo, tornando os alunos capazes de observar o mundo a seu redor e tirar conclusões, com autonomia e independência (DeBoer, 2000). Com o passar do tempo, foram surgindo outras iniciativas em educação em ciência e o termo passou a assumir vários significados. De uma forma ampla, o termo passou a significar desde a difusão de conhecimentos gerais da ciência em espaços não formais de aprendizagem até a formação em ciências dentro da escola.

Especificamente nos Estados Unidos, o incentivo à educação em ciência cresceu exponencialmente na década de 50, durante a Guerra Fria, uma vez que os governantes precisavam do apoio da opinião pública para o desenvolvimento de pesquisas científicas e tecnológicas (Laugksch, 2000). Diante do avanço tecnológico russo e da ameça de ser ultrapassado tecnologicamente, o governo norte americano entendeu que o progresso científico dependia do conhecimento sobre ciência da população e dessa forma era necessário um grande investimento por parte do governo em educação em ciência para o público geral (DeBoer, 2000). Nesse contexto surge o termo “Alfabetização Científica” (do inglês "Scientific Literacy”), que designa o conhecimento mínimo que o público geral deveria ter sobre ciência (Durant, 2005). Diversas abordagens existem para este termo, mas, de modo geral, essas abordagens enfatizam principalmente os seguintes aspectos: 1) Conhecer o conteúdo da ciência, suas principais ideias, conceitos e processos; 2) Entender os métodos científicos, desenvolver capacidade de observação e investigação; 3) Compreender a ciência como prática social, seus objetivos gerais, suas limitações e seu papel na sociedade (Durant, 2005). Mais recentemente, tem-se destacado também a importância da alfabetização científica para tratar de problemas mais atuais, como por exemplo sobre conservação e uso dos recursos naturais, enfatizando a importância do aumento do conhecimento sobre sustentabilidade por parte da população em geral (Colucci-Gray et al., 2006).

O termo "Alfabetização Científica” é mais comumente utilizado nos Estados Unidos, e tem o mesmo significado do termo "Cultura Científica” (do francês “Culture Scientifique”), muito usado na França, e da expressão "Compreensão pública da ciência” (do inglês "public understanding of science”), mais usado na Inglaterra (Durant, 2005). No Brasil, os termos mais utilizados são Educação em Ciência, no âmbito da educação formal, desde o ensino de ciências nas escolas até o desenvolvimento do pensar científico por parte dos alunos, e Divulgação Científica, no que se refere à educação não-formal, com iniciativas que despertam o interesse científico por parte do público geral. De qualquer forma, independente do termo utilizado, todas as propostas buscam o aumento do conhecimento científico e da formação do pensar científico por parte da sociedade como um todo (Reis, 2006).

Após esta rápida introdução sobre alguns termos relacionados à educação em ciência, apresentaremos um pouco sobre a importância e a necessidade da formação da consciência científica, seguiremos definindo as "novas" tecnologias e finalizaremos exemplificando formas de uso desta tecnologia para a educação em ciência.

\section{IMPORTÂNCIA E NECESSIDADE DO “PENSAR CIENTÍFICO”}

A formação de consciência científica é cada vez mais importante, uma vez que a ciência e a tecnologia têm tido intensa interferência na nossa sociedade atual. Emerge, então, a necessidade da difusão de conceitos científicos, de atitudes e valores da ciência, da incorporação desses valores no cotidiano das pessoas, da disseminação do pensar científico e da postura crítica e indagativa diante do que ciência e tecnologia apresentam à sociedade. É o caráter interdisciplinar da Educação em Ciência, unindo além de ciências, ética, sociologia, filosofia, entre outras, que permite a promoção da cultura científica entre cidadãos, tornando-os capazes de participar ativamente de uma sociedade democrática (Cachapuz et al., 2004). 
Contribuir para a formação de cidadãos cientificamente mais cultos, promovendo a compreensão da relação Ciência-Tecnologia-Sociedade-Ambiente e o desenvolvimento de competências para resolver problemas, gerir conflitos, tomar decisões e fazer escolhas conscientes, seria a meta da educação em ciência. Podemos reconhecer a importância da educação em ciência em dois níveis: geral e individual, segundo Laugksch (2000). No nível geral encontram-se fatores ligados a maior probabilidade de termos cidadãos que sigam a carreira científica, que apoiem projetos ligados a ciência e que tenham melhores expectativas e compreensão do que a ciência pode produzir. No nível individual a importância seria ligada a melhoria da confiança, competência e empregabilidade dos cidadãos no dia-a-dia de uma sociedade moderna e altamente tecnológica. Além disso, como boa parte do financiamento da ciência é público, cidadãos com maior conhecimento científico poderão ter uma participação mais ativa nas decisões políticas que envolvem tanto a distribuição de recursos quanto temas de maior apelo popular, como por exemplo o uso de células tronco em pesquisa científica.

A educação em ciência torna-se, desta forma, uma necessidade vital para o exercício da cidadania de maneira plena. O reconhecimento desta necessidade expressa-se em diferentes iniciativas que visam à difusão e à popularização da ciência, como por exemplo, criação de espaços de ciência e iniciativas de fomento a projetos na área de educação em ciência.

Apesar da reconhecida importância que a alfabetização científica tem na vida das pessoas, como apontado por Gago (1997 apud Cachapuz et al., 2002), “o ensino básico dá aos jovens uma caricatura das ciências ... ensinando-lhes muitos nomes e poucos porquês...”. Em outras palavras, Cachapuz (2007) comenta que a Ciência que se legitimou nos currículos, no ensino e nos manuais escolares, está desligada do mundo a que pertence.

Neste contexto, é da máxima importância que o ensino das ciências seja contextualizado e significativo. Além disso, a alfabetização científica deve ser possível de ser alcançada, processual e individualmente, em qualquer fase da vida de um cidadão não apenas por meio da aprendizagem das ciências na educação formal escolar mas também por meio de experiências especificamente desenvolvidas para isso, em diferentes formatos e espaços, sempre privilegiando o caráter lúdico e agradável do aprendizado espontâneo e fortemente contextualizado.

\section{TECNOLOGIA E EDUCAÇÃO FORMAL}

Nos dias de hoje o termo "tecnologia” é tido como sinônimo de ferramentas ou máquinas que usamos em nossa rotina como computadores, celulares e tablets. Mas a origem desse termo é muito mais antiga e pode ser relacionada ao uso sistemático de qualquer tipo de conhecimento organizado (Luppicini, 2005; Nonato, 2006). Sendo assim, atividades realizadas e organizadas pelo homem que variam desde o domínio do fogo por nossos ancestrais até a informática podem ser consideradas como tecnologias e são usadas de forma a registrar ou otimizar algum tipo de atividade.

O ramo acadêmico que estuda a educação no contexto tecnológico da educação é chamado normalmente de Tecnologia Educacional (em inglês, Educational Technology) e assim como a origem do termo tecnologia essa área não se limita ao uso de ferramentas. Segundo Miranda (2007),

“[A Tecnologia Educacional] É um domínio da educação que teve as suas origens nos anos 40 do século XX. (...) O termo não se limita aos recursos técnicos usados no ensino mas a todos os processos de concepção, desenvolvimento e avaliação da aprendizagem.”

Uma expressão muito utilizada tanto na literatura nacional quanto internacional para designar ferramentas consideradas modernas na educação é “novas tecnologias”. O termo “novo” além de não especificar que tipos de ferramentas estão sendo tratadas pode passar uma ideia temporal errada, já que recursos técnicos considerados novos hoje em dia poderão ser ultrapassados no futuro. A expressão “Tecnologias digitais” ou “Ferramentas digitais” utilizada por Säljö (2010) para se referir a recursos como computadores e internet que começaram a ser utilizados para motivos 
educacionais no final da década de 1970 e 1980 pode descrever melhor o que consideramos como “novas” tecnologias nos dias de hoje.

A forma como ensinamos e aprendemos em sala de aula, na educação formal, não é algo imutável, e vem sofrendo algumas transformações ao longo do tempo. O uso de máquina de escrever, por exemplo, pode parecer algo ultrapassado hoje em dia, mas já foi considerado com uma grande inovação tecnológica para a educação. Por isso, ao entendermos que tecnologias aparentemente revolucionárias já foram integradas em sala de aula podemos facilitar a adoção de tecnologias consideradas novas (Kalmbach, 1996). Devemos olhar para o passado para entendermos melhor o presente, pois promessas de revoluções na educação através de novas tecnologias não são comuns apenas nos dias de hoje.

Entretanto, segundo Mishra et al. (2009) vários autores da área da educação discutem como "novas" tecnologias poderiam ser revolucionárias, mas boa parte delas nunca chegou a ser usada efetivamente em sala de aula. $\mathrm{O}$ fracasso do uso efetivo de novas tecnologias em sala de aula não ocorreu por falta de potencial das inovações, mas principalmente por três aspectos: 1) O uso de novas tecnologias de forma instrucionalmente efetiva requer conhecimento específico em como a tecnologia pode ser usada com objetivo pedagógico; 2) O uso de novas tecnologias normalmente encontra resistência dos educadores que acreditam que elas podem fazer mais mal do que bem; 3) A maior parte das inovações focaram mais na própria tecnologia do que em como abordar questões fundamentais relacionadas a melhoria do ensino e aprendizagem (Mishra et al., 2009).

Os educadores do início do século XXI estão pressionados para que hajam mudanças no sistema de ensino e existe também uma grande espectativa de que as “novas” tecnologias trarão soluções rápidas e inovadoras para a educação (Moran, 2000). Para que o uso de tecnologias como internet, simulações, redes sociais e jogos educativos seja focado na melhoria do ensino e aprendizagem é preciso pensar não somente em como integrar as ferramentas na sala de aula, mas o contexto do seu uso. O ramo acadêmico da Tecnologia Educacional tem discutido nas últimas décadas principalmente como provar a efetividade do uso de tecnologias, mas sem especificar quais tecnologias realmente funcionam na facilitação do aprendizado, em que maneiras, em quais situações, em qual contexto, para quem e porquê (Ross, 2010). A inserção simples em sala de aula de ferramentas digitais que são substituídas em escalas cada vez mais curtas (ontem o estado da arte era o notebook, hoje o tablet... qual será amanhã?) pode não trazer o ganho esperado para o aprendizado.

Em um mundo onde a evolução tecnológica ocorre em escala exponencial e cada vez mais toma conta do dia-a-dia dos alunos, o aprendizado não é mais linear já que a informação está disponível de forma rápida e relativamente barata através da internet. Nesse contexto os alunos devem ser colocados em situações que os obriguem a pensar, refletir e entender as várias dimensões de um fenômeno (Martins, 2010). Segundo Moran (2004), além de uma nova sala de aula equipada com tecnologias digitais, uma educação inovadora deve ter uma alteração radical do papel do professor:

“O professor passa de uma 'babá', de dar tudo pronto, 'mastigado', para ajudar o aluno, de um lado, na organização do caos informativo, na gestão das contradições dos valores e visões de mundo, enquanto, do outro lado, o professor provoca o aluno, o ‘desorganiza', o desinstala, o estimula a mudanças, a não permanecer acomodado na primeira síntese.”

Existem evidências consideráveis que a educação baseada em padrões e limitações governamentais apresenta um potencial de inibir a autonomia e criatividade de professores e estudantes em sala de aula (DeBoer, 2000). No contexto de alteração do comportamento do educador auxiliado pelas tecnologias digitais, as disciplinas que mais tendem a ganhar são aquelas ligadas a área científica que demandam o exercício do pensamento crítico e multirreferencial.

Além do importante papel em sala de aula, as tecnologias digitais podem ter grande contribuição através da educação informal. A maior parte do conhecimento estimulado e testado em sala de aula tem como base meios impressos. Meios digitais como televisão, video games e internet podem ser uma importante ferramenta 
para estimular a inteligência visual dos alunos que têm grande relevância em áreas científicas e tecnológicas (Greenfield, 2009).

\section{EDUCAÇÃO EM CIÊNCIA E AS “NOVAS” TECNOLOGIAS}

A partir dessas muitas novas maneiras de aprender e ensinar, que alteram, inclusive, o alcance da educação em termos de número de pessoas e localização das mesmas, abrem-se oportunidades para a educação em ciência. As aprendizagens deixam de ocorrer prioritariamente no contexto real da sala de aula e o professor tem reduzida a posição de destaque no processo. Individualmente e em grupo; em casa, no trabalho e na escola; crianças, jovens e adultos de todas as idades podem aprender ciência!

O ambiente digital com as diferentes possibilidades de interação e formas de linguagem permite que a educação em ciência seja um processo que se construa em diversas frentes e em diferentes formatos. Resultados de pesquisa científica podem chegar ao público geral em uma linguagem acessível por meio de artigos de divulgação, que são disponibilizados na internet. Frutos destas mesmas pesquisas ou de projetos especificamente desenhados para educação em ciência, há na web uma grande quantidade de “objetos de aprendizagem” que têm sido recursos extremamente valiosos para o aprendizado das ciências também na educação formal.

Abaixo, exemplificamos algumas importantes iniciativas de diferentes formatos que visam a contribuir para a educação em ciência em espaços formais e não formais de aprendizagem.

\section{Instituto Ciência hoje - cienciahoje.uol.com.br}

O Instituto Ciência Hoje (ICH) é uma sociedade civil sem fins lucrativos criada em 2003. Sua história começa em 1982, com o lançamento da revista Ciência Hoje, vinculada à Sociedade Brasileira para o Progresso da Ciência (SBPC). Além da CH, hoje o Instituto é responsável por uma série de publicações de divulgação científica, como a Ciência Hoje das Crianças e os livros da série Ciência Hoje na Escola. Além disto, o Instituto mantém um portal de divulgação científica na internet, a Ciência Hoje On-line.

\section{ScienceBlogs Brasil - scienceblogs.com.br}

O ScienceBlogs Brasil é a versão em língua portuguesa da maior rede de blogs de ciência do mundo, o ScienceBlogs (http://scienceblogs.com/). No Brasil, o portal nasceu em 2008 apresentando outro nome (Lablogatórios), mas logo ganhou projeção internacional e foi convidado a fazer parte da rede internacional de blogs ScienceBlogs, que também apresenta portais com blogs em alemão e espanhol. Hoje em dia o ScienceBlogs Brasil conta com mais de 40 blogs que se distribuem nas diversas áreas do conhecimento científico, sendo atualizados por alunos de graduação, pós-graduação e professores universitários de diversas universidades do Brasil e de Portugal. Além de publicar artigos que discutem a ciência básica, os blogs científicos possuem uma característica interessante pois são pessoais, abrindo a possibilidade dos autores discutirem o dia-a-dia dos laboratórios e universidades, política e cultura, aproximando o público do aspecto humano de quem faz ciência.

\section{Museu Virtual de Ciência e Tecnologia da Universidade de Brasília - www.museuvirtual.unb.br}

O Museu Virtual de Ciência e Tecnologia da Universidade de Brasília é uma ferramenta de divulgação científica, reunindo oito grandes seções com diversificadas amostras da produção científica da UnB: o Museu de Anatomia, da Faculdade de Medicina; o Herbário, do Departamento de Botânica; a Experimentoteca, do Instituto de Física; o Laboratório de Pesquisas em Ensino de Química; o Observatório Sismológico; o Museu de Geociências; e as coleções do acervo zoológico. O Museu abriga ainda as chamadas exposições virtuais, que têm caráter interativo e feição lúdica. 


\section{Rede Interativa Virtual de Educação - RIVED - rived.mec.gov.br}

RIVED é um programa do MEC com objetivo de produzir e disponibilizar conteúdos pedagógicos digitais, na forma de objetos de aprendizagem para melhorar a aprendizagem das disciplinas da educação básica e a formação cidadã do aluno. O RIVED ainda realiza capacitações sobre a metodologia para produzir e utilizar os objetos de aprendizagem nas instituições de ensino superior e na rede pública de ensino.

\section{Ciência em Tela - www.cienciaemtela.nutes.ufrj.br}

Ciência em Tela é uma revista eletrônica semestral vinculada à Rede de Investigação Divulgação e Educação em Ciências (RIDEC) da Universidade Federal do Rio de Janeiro (UFRJ), com a proposta de estreitar relações e de divulgar ações desenvolvidas em espaços educativos formais e não formais, tais como universidade, escola, museus, centros de ciência, mídia, ONGs etc.

A revista publica artigos de pesquisa, ensaios, relatos de experiência e de produção de material didático, valorizando a participação de professores da escola básica e do ensino superior, educadores que atuam em espaços não formais, cientistas, pesquisadores em ensino e divulgadores de ciência, tanto como autores quanto como pareceristas.

\section{Portal TECA - teca.cecierj.edu.br}

O material didático produzido pela Fundação Cecierj pode ser encontrado no TECA, um portal que reúne imagens, animações, vídeos, áudios e textos com uso liberado para o público em geral. São mais de 1.000 arquivos cadastrados até o momento, além de animações sobre diversos temas.

\section{Ciência \& Ensino - www.ige.unicamp.br/ojs/index.php/cienciaeensino}

A Ciência \& Ensino (versão impressa ISSN 1414-5111) foi lançada em 1996 pelo gepCE (Grupo de Estudo e Pesquisa em Ciência \& Ensino) então com apoio da Faculdade de Educação da Unicamp. Em 2006, aos 10 anos, foi criada a versão eletrônica (on line). A revista destina-se, prioritariamente, a professores de ciências do ensino fundamental e médio e seus formadores, constituindo um espaço acadêmico de leitura e escrita do professor e do futuro professor.

Um último aspecto que gostaríamos de salientar refere-se à importância destas "novas” tecnologias para a aprendizagem ao longo da vida (lifelong learning - LLL, em inglês). O conceito de aprendizagem ao longo da vida é usado de diversas formas na literatura, mas uma analogia importante é de que estamos sempre reconstruindo nossas teorias ao longo da vida e só paramos de aprender quando morremos (Aspman \& Chapman, 2007). A facilidade de acesso em termos de tempo e local, o potencial de atualização das informações e as ferramentas de interatividade hoje disponíveis facilitam enormemente a aprendizagem, que, desta forma, pode se dar ao longo da vida, não só informalmente, mas, inclusive, como educação formal em cursos na modalidade a distância, cada vez mais comuns. E por que aprender a vida toda? Porque "o futuro permanece aberto e imprevisível”, nos diz Morin (2000). Podemos nos reconstruir por meio da educação e devemos reconstruir nosso mundo, "cuidar" dele, e isso, só “com ciência”!

\section{REFERÊNCIAS BIBLIOGRÁFICAS}

ASPIN, D. N.; CHAPMAN, D. J. D. Lifelong learning: Concepts and conceptions. In: ASPIN, D. N (org.). Philosophical perspectives on lifelong learning. Springer Netherlands, 2007. p. 19-38. 
CACHAPUZ, A.F.; PRAIA, J.; JORGE, M. Ciência, Educação em Ciências e Ensino de Ciências. Ministério da Educação. Lisboa, 353 pp., 2002.

CACHAPUZ, A.F.; PRAIA, J.; JORGE, M. Da Educação em Ciência às Orientações para o Ensino das Ciências: Um Repensar Epistemológico. Ciência \& Educação, v. 10, n. 3, p. 363-381, 2004.

CACHAPUZ, A.F. Educação em ciência: que fazer? Seminários e Colóquios, CNE, Lisboa, p. 239-250, 2007.

COLUCCI-GRAY, L.; CAMINO, E.; BARBIERO, G.; GRAY, D. From Scientific Literacy to Sustainability Literacy: An Ecological Framework for Education. Science Education, v. 90, n. 2, p. 227-252, 2006.

DEBOER, G.E. Scientific Literacy: Another Look at Its Historical and Contemporary Meanings and Its Relationship to Science Education Reform. Journal of Research in Science Teaching, v. 37, n.6, p. 582-601, 2000.

DURANT, J. O Que é Alfabetização Científica? In: MASSARANI, L.; TURNEY, J.; MOREIRA, I.C. (Org.). Terra Incógnita: A Interface entre Ciência e Público. Rio de Janeiro: Vieira \& Lent : UFRJ, Casa da Ciência: FIOCRUZ, 2005. p. 13-26.

GREENFIELD, P.M. Technology and Informal Education: What Is Taught, What Is Learned. Science, v. 323, p. 69-71, 2009.

KALMBACH, J. From Liquid Paper to Typewriters: Some Historical Perspectives on Technology in the Classroom. Computers and Composition, v. 13, p. 57-68, 1996.

LAUGKSCH, R.C. Scientific Literacy: A Conceptual Overview. Science Education, v. 84, p. 71-94, 2000.

LUPPICINI, R. A Systems Definition of Educational Technology in Society. Educational Technology \& Society, v. 8, n. 3, p. 103-109, 2005.

MARTINS, J.B. Reflexões em Torno do Papel do Educador no Contexto das Novas Tecnologias. Revista Iberoamericana de Educação, v. 54, n.3, p. 1-6, 2010.

MIRANDA, G.L. Limites e Possibilidades das TIC na Educação. Sísifo / Revista de Ciências da Educação, v. 3, p. 41-50, 2007.

MISHRA, P.; KOEHLER, M.J.; KERELUIK, K. Looking Back to the Future of Educational Technology. TechTrends, v. 53, n. 5, p. 48-53, 2009.

MORAN, J. M. Ensino e aprendizagem inovadores com tecnologias. Informática na Educação: Teoria e Prática, v. 3, n. 1, p. 137-144, 2000.

MORAN, J. M. A contribuição das tecnologias para uma educação inovadora. Contrapontos, v. 4, n. 2, p. 347356, 2004.

MORIN, E. Cabeça Bem-Feita; repensar a reforma, reformar o pensamento. Rio de Janeiro: Bertrand Brasil, 2000.

NONATO, E.R.S. Novas tecnologias, Educação e Contemporaneidade. Práxis Educativa, v. 1, n. 1, p. 77-86, 2006.

REIS, P. Ciência e Educação: Que Relação? Interacções, v. 3, p. 160-187, 2006.

ROSS, S.M.; MORRISON, G.R.; LOWTHER, D.L. Educational Technology Research Past and Present: Balancing Rigor and Relevance to Impact School Learning. Contemporary Educational Technology, v. 1, n. 1, p. 17-35, 2010.

SÄLJÖ, R. Digital tools and challenges to institutional traditions of learning: technologies, social memory and the performative nature of learning. Journal of Computer Assisted Learning, v. 26, p. 53-64, 2010. 